\section{Exclusión social y pobreza: perspectivas teóricas y percepciones de jóvenes excluidos de la ciudad de Medellín}

Social exclusion and poverty: theoretical perspectives and perceptions of excluded young people from Medellín.

\author{
Beatriz García-ChacóN ${ }^{* *}$ \\ JenNy ACEVEDO-Valencia \\ Santiago Morales-Mesa \\ Olga Arboleda-Álvarez
}

\footnotetext{
Este artículo es resultado de la investigación "Estrategias de sobrevivencia de jóvenes en condiciones de pobreza de la ciudad de Medellín" realizado entre 2014 y 2016 por el grupo de investigación Laboratorio Universitario de Estudios Sociales (LUES) de la Fundación Universitaria Luis Amigó (Funlam) de Medellín, Colombia. La investigación fue financiada por la Federación Internacional de Universidades católicas FIUC y la Funlam.

** Docentes Funlam. Transversal 51 A No 67B - 90, Medellín, Colombia. Correos electrónicos: beatriz.garciach@amigo.edu. co; jenny.acevedova@amigo.edu.co; smorales@funlam.edu.co; oarboled@funlam.edu.co.
}

\section{Resumen}

En este artículo se presenta una aproximación teórica sobre los conceptos de pobreza y exclusión, rescatando su carácter multidimensional y estructural, haciendo énfasis en la necesidad de comprender estos fenómenos más allá de la mirada economicista. Esto se articula a los análisis de un ejercicio investigativo cualitativo, realizado con jóvenes en condición de pobreza de Medellín, en el cual se rescata sus percepciones sobre las dimensiones de estos fenómenos en sus experiencias vitales.

Palabras clave: Exclusión social, pobreza, jóvenes, desigualdad

\begin{abstract}
This article presents a theoretical approach on the concepts of poverty and exclusion taking into account its structural and multidimensional character, empha-sizing the need to understand these phenomena beyond the economistic look. This is articulated to the analysis of a qualitative research exercise, carried out with young people in poverty in Medellin, which shows their perceptions about the dimensions of these phenomena on their own life experiences.
\end{abstract}

Key words: Social exclusion, poverty, youth, inequality 


\section{Introducción}

En América Latina se configuran múltiples manifestaciones de pobreza y exclusión, sus ciudades constituyen vitrinas de desigualdad social, de pobreza creciente y son muestras del fracaso de las políticas de contención, inclusión e integración social, económica, política y cultural. En estos contextos de alta precariedad económica y de fragilidad social, la juventud es uno de los sectores sociales mayormente expuestos a la pobreza y a la exclusión (Makowski 2008).

Datos de Unicef (2008) sobre América Latina y el Caribe, que mapean la situación de los jóvenes latinoamericanos, plantean que en la región existen 106 millones de jóvenes entre 15 y 24 años de edad, el mayor número de jóvenes en la historia de la región. La pobreza los afecta en forma desproporcionada, con un promedio de $39 \%$ que vive en situación de pobreza, de los cuales 15 millones de adolescentes se encuentran en pobreza extrema, es decir, con menos de \$1 al día.

La brecha entre los sectores de la población de altos ingresos y la de bajos ingresos en los centros urbanos afecta cada vez más las vidas de los adolescentes. Alrededor de un $25 \%$ a un $32 \%$ de la población de 12 a 24 años de edad en la región vive con factores de riesgo como la deserción escolar, la maternidad adolescente, el desempleo, la adicción a las drogas o problemas con las autoridades.

Por otro lado, los adolescentes encaran diversos tipos de explotación, muchas veces son reclutados para hacer trabajos peligrosos, son presa del crimen organizado incluyendo el tráfico de drogas y son traficados para trabajo forzado, conflictos armados o como trabajadoras sexuales, incluyendo pornografía.

En América Latina y el Caribe las niñas y las mujeres siguen enfrentando costumbres arraigadas de estereotipos de género, tales como la división de labores de acuerdo al sexo, distribución desigual de las riquezas y la violencia. En el aspecto económico, las mujeres ganan $30 \%$ menos que los hombres en la región.

Así, la experiencia de muchos jóvenes en Latinoamérica está marcada por la dificultad y la escasez de oportunidades que se manifiestan en la falta de empleo, la inseguridad pública, las dificultades para ingresar a la educación y continuar estudiando, la insuficiente y deficiente prestación de servicios de salud, los pocos espacios recreativos, deportivos y culturales, las dificultades para acceder a una nutrición completa y de calidad, la ruptura de lazos familiares y sociales y la estigmatización social que los discrimina.

La situación de los jóvenes acontece en un contexto económico neoliberal en el que se destaca el desarrollo de tendencias como la globalización, el progreso científico-tecnológico y el avance de la sociedad de la información, las cuales están orientadas a imponer la concentración en pocas manos del poder financiero, tecnológico, político y militar. Esta concentración de poderes provoca un aumento generalizado de sectores discriminados y excluidos en lo social, lo político, lo cultural y lo económico, generando un deterioro mayor en la condición de dignidad de grandes grupos poblacionales alrededor del planeta. La incidencia de los procesos de globalización y neoliberalismo económico en diferentes esferas de la realidad, sugieren la incorporación de 
nuevos elementos en los análisis que se hacen sobre los fenómenos sociales.

El escrito que se presenta a continuación contiene una reflexión sobre la pobreza y la exclusión social en el contexto actual y pretende articular esta discusión a algunos hallazgos generados en un proceso de investigación que se desarrolló con grupos de jóvenes en condiciones de pobreza de la ciudad de Medellín (Colombia) entre febrero de 2014 y junio de 2016.

Este estudio se realizó simultáneamente en cuatro países: México, Honduras, Ecuador y Colombia, con la participación de seis universidades, y tiene como campo de estudio poblaciones en condiciones de pobreza y sectores excluidos.

Los hallazgos investigativos y las reflexiones que se presentan en este artículo, recuperan la voz y la mirada de los jóvenes que participaron en la investigación, quienes se vincularon a este ejercicio académico a través de estrategias metodológicas como talleres, recorridos barriales, cartografías, escritos vivenciales, discusiones grupales; con la pretensión de conocer sus contextos de vida y visibilizar las dimensiones de la exclusión y las formas en que ellos perciben, sienten, manifiestan y la viven en su cotidianidad.

La investigación se realizó en coherencia con un enfoque cualitativo y una metodología dialógico-interactiva. Desde esta perspectiva de investigación social la naturaleza de la realidad social es una construcción humana dialógica cuyos significados son construidos de forma comunicativa a través de la interacción entre las personas; en este sentido la realidad social se conoce en el diálogo, y el conocimiento es producto y productor de nuevas interacciones comunicativas. Este enfoque metodológico se genera relacionando tres conceptos: diálogo, interacción y comunicación crítica, donde las personas involucradas en el proceso participan develando los hechos, negociando comprensiones, ampliando explicaciones y proponiendo prácticas capaces de transformar. En este orden de ideas los resultados que a continuación se presentan rescatan la voz, la mirada, la subjetividad y la reflexión de los jóvenes que participaron en el estudio, a quienes se podrá leer a través de sus respectivos testimonios.

El artículo se organiza en cuatro apartados, en el primero se abordan teóricamente los conceptos de pobreza y exclusión social, en el segundo se conceptualiza la exclusión como proceso estructural y estructurante, en el tercero se plantean la dimensiones de la pobreza en sus ámbitos objetivo y subjetivo, se caracterizan los jóvenes que participaron en el estudio y los territorios que habitan y se incluyen análisis que abordan las dimensiones de la pobreza retomando los testimonios de la población juvenil en clave de las lecturas teóricas y, por último, se dibujan unas conclusiones del artículo en clave de rutas de interpretación necesarias para el abordaje de la pobreza y la exclusión en los contextos actuales.

\section{Pobreza y exclusión social}

Tradicionalmente la pobreza ha sido estudiada de manera unidimensional, privilegiando la mirada de las carencias, de los bajos ingresos, del ínfimo ${ }^{1}$ consumo de las personas. Igualmente,

Es un consumo ínfimo condicionado por el contexto y no por una decisión personal. 
el concepto ha sido usado para hacer referencia a la falta de recursos materiales-económicos suficientes para atender las necesidades básicas de supervivencia y, en general, alude a factores materiales cuantificables.

La pobreza suele ser asociada a personas que carecen de recursos económicos o que los tienen de manera insuficiente, y en sus aproximaciones se utilizan parámetros de medición vinculados al mundo de la producción y el consumo de bienes materiales, esto significa que en los estudios sobre la pobreza se ha privilegiado una mirada económica de la misma y desde una perspectiva funcional que da pie a una serie de programas para "combatirla", porque la pobreza, por su aspecto disfuncional al sistema económico, se ha concebido como un freno para el desarrollo.

Esta perspectiva funcional al sistema genera intervenciones, diagnósticos, mediciones y diseño de políticas públicas que no afectarán realmente las estructuras económicas que están determinando la inserción precaria de sectores de la población. Una lectura ingenua de la pobreza y la exclusión, que no lee a las personas en su potencia, ni lee las condiciones de sometimiento que perpetúan la desigualdad en las "dotaciones iniciales"2 que impiden, como lo señala Amartya Sen (2000), la potenciación de sus capacidades.

La percepción de la pobreza como fenómeno de escala global "no fue más que el resultado de operaciones estadísticas comparativas, la primera de las cuales se realizó apenas en 1940" (Sachs 1990: 9). Al respecto Rahnema (1991), citado por Escobar, describe que:

Las dotaciones iniciales están compuestas por el capital económico, cultural y social acumulado por las personas o las familias.
Una ruptura en la concepción sobre la pobreza como global fue efectuada por la definición de las dos terceras partes del mundo como pobres después de 1945. Si en las economías de mercado los pobres eran definidos como carentes de aquello que los ricos tenían en términos de dinero y posesiones materiales, los países pobres llegaron a ser definidos en forma análoga en relación con los patrones de riqueza de las naciones económicamente más adelantadas. Esta concepción económica de la pobreza encontró un parámetro ideal en el ingreso anual per cápita (2007: 51).

La percepción de la generación de riqueza indefinida como un valor humano es reciente y se produce gracias a la combinación de factores como las nuevas tecnologías industriales, la energía del carbón y del petróleo, la organización de las fuerzas del mercado, la migración y desplazamientos, la urbanización y el abandono del campo, el cambio en la estructura familiar y la división del trabajo en un mercado que es global. Toda esta riqueza generada no se ha redistribuido justamente generando mayores desigualdades y exclusiones.

La pobreza, la desigualdad y la exclusión social se han hecho un fenómeno común, su existencia se ha naturalizado, de manera que produce una suerte de opacidad que no deja ver causas y condiciones que la generan y mantienen, generando indiferencia, rutinización y una especie de anestesia ética y social que lleva a que ya no se presente una indignación ante la injusticia rampante que se evidencia en ciudades, regiones y países.

Por su parte. los pobres, los expulsados, los "despreciados" se han vuelto parte del paisaje urbano, se tornan en seres "desechables", en "fantasmas que deambulan" sin ser vistos por los ciudadanos y los gobernantes (Makowski 2008). Si estos adquieren alguna visibilidad se los ve como lo anormal, generando repulsión, porque se los asocia con el descontrol, lo sucio, 
lo prescindible, lo prostituido y lo criminal, aspectos todos que degradan lo público y acrecienta su inseguridad.

Esto es discutido por los políticos, el sector gubernamental y no gubernamental, los académicos y la iglesia, entre otros actores, en espacios internacionales, nacionales y locales; no obstante en la actualidad se hace necesario interpelar y problematizar la realidad y la idea de la pobreza y la exclusión que se viene entendiendo como un fenómeno inevitable, una catástrofe natural.

Tal como lo expresan Cortina (2009) y Freire (2001) no se trata de un acontecimiento natural, sino de un producto social del que somos responsables. La pobreza no es solo de quienes la causan directamente, ni de aquellos que pueden disfrutar de riquezas porque otros se los permiten "hay pobres porque hay ricos", sino también de los que, por desinterés, no hacen nada para evitarla, cuando son conscientes de que es perversa y de que hay recursos para acabar con ella (Cortina 2009).

Aún hoy se referencian intelectuales como la economista norte americana Mollie Orshansky ${ }^{3}$, quien argumenta que "la pobreza es un juicio de valor" afirmando que "la pobreza, como la belleza, está en el ojo de quien la percibe". Si bien los conceptos como pobreza, desigualdad y necesidades básicas tienen una dimensión y carga valorativa -cultural, religiosa, ética- no se puede negar que estos conceptos poseen un contenido y una expresión descriptiva que objetiva realidades socioeconómicas, culturales y ambientales marcadas por la desigualdad y la exclusión.

Economista y experta en estadística estadounidense que se especializó en los estudios de los umbrales de la pobreza.
Al respecto mencionan Spicker et al.: En toda la historia del capitalismo y del imperialismo,
la pobreza en el mundo jamás alcanzó una dimensión
tan masiva y escalofriante como a finales del siglo XX y
comienzos del presente. Nuestro subcontinente, dentro
del concierto de los conjuntos sociales y culturales de
nuestro planeta, es uno de los espacios, luego de África,
donde la gran mayoría de su población es pobre. A esto
se suma que la desigualdad, uno de los factores más
importantes de la producción de pobreza, es la más
extrema del mundo.

En los últimos treinta años, el proceso de empobrecimiento y profundización de las viejas pobrezas ha sido tan veloz y marcado en el mundo -pero particularmente en América Latina y el Caribe- que ha modificado estructuralmente nuestras sociedades, sumiendo en el hambre, la exclusión, la descalificación y la falta de ilusión sobre un futuro próspero a un conjunto cada vez más amplio de seres humanos (2009: 39).

La pobreza como la exclusión social se conciben como fenómenos producidos por la interacción de "una pluralidad de procesos o factores elementales que afectan a los individuos y grupos humanos impidiéndoles acceder a un nivel de calidad de vida decente y a participar plenamente, según sus propias capacidades en los procesos de desarrollo" (Castillo 2008: 243).

En la misma dirección, Amartya Sen ha criticado las posiciones unidimensionales economicistas y las relativistas mencionadas anteriormente, y refuerza su posición, de entender la pobreza desde una perspectiva multidimensional recurriendo a Marx, quien respecto a este tema aceptó la existencia de una medida de subsistencia, donde "las llamadas necesidades básicas" tienen "un elemento histórico y moral", reconociendo que, "en un país determinado, en un período determinado, el promedio de cantidad de medios de subsistencia es prácticamente conocido" (Sen 1982: 446). De aquí que la dimensión múltiple del empobrecimiento incluye la privación material, la situación adversa en 
lo familiar-relacional, el empleo, el hábitat (urbano-territorial en la mayoría de los casos), la transformación y la ruptura de vínculos sociales y políticos que restringen la participación y la interacción, generando desigualdad (Castillo 2008: 132).

Desde una perspectiva multidimensional de la pobreza se considera que ésta puede afectar, no solo los ingresos y la capacidad de consumo, sino los aspectos humanos como:

\begin{abstract}
El poder vivir hasta el final de una vida humana completa; tener buena salud, estar suficientemente alimentado, tener alojamiento y libertad de movimiento; evitar el dolor innecesario y perjudicial, tener experiencias placenteras; usar los cinco sentidos, imaginar, pensar y razonar; relacionarse con personas y cosas por fuera de nosotros, amar a quienes nos aman y se preocupan de nosotros, sentir pena por su ausencia; formarse una concepción del bien y comprometerse a una reflexión crítica acerca de la planificación de la propia vida; vivir con y para otros, reconocer y mostrar preocupación por otros seres humanos, comprometerse en varias formas de interacción familiar y social; vivir preocupado por animales, plantas, y el mundo de la naturaleza; reír, jugar, disfrutar de actividades recreativas; vivir la propia vida y la de nadie más en el propio entorno y contexto (Nussbaum 1998: 71).
\end{abstract}

La pobreza como carencia, negación de capacidades y derechos, se genera históricamente en un contexto económico, sociopolítico y ambiental que configura una organización de lo social que impide a grupos vulnerables de la población (mujeres, niños, jóvenes, ancianos, personas en situación de discapacidad y determinadas etnias) ejercer capacidades y derechos, lo que tiene como consecuencia que las personas no realicen sus vidas como realmente quieren.

En este orden de ideas, la pobreza puede ser comprendida como una ruptura o inadecuado funcionamiento del sistema socioeconómico y político que debiera garantizar la plena ciudadanía. La pobreza y la exclusión como discursos diferenciados que abordan situaciones y condiciones concretas de vida de las personas, han tenido puntos de encuentro y desencuentro. Las explicaciones asociadas a una y otra requieren de una mirada que problematice las visiones meramente economicistas de estos fenómenos, por ello se presentan en los siguientes párrafos algunas aproximaciones sobre el concepto de exclusión social que pretenden ampliar la mirada sobre la pobreza.

Es importante resaltar que en el contexto de las ciencias sociales, el término exclusión social se introdujo dadas las limitaciones del concepto de pobreza para dar cuenta del carácter relacional y multidimensional del fenómeno, además de incorporar aspectos de análisis relacionados con las transformaciones económicas propias de los últimos cuarenta años. A pesar que el concepto de exclusión social ha sido usado con diferentes acepciones, es común encontrar una relación directa entre exclusión y desigualdad.

Autores como Juárez (1995) y García (2006) hacen referencia a la exclusión como un "espiral de precariedad" relacionado con un rango amplio de aspectos de privación y de desventajas que se van acumulando en el tiempo y se extienden de generación en generación. La idea de espiral está dada por la confluencia de múltiples dimensiones en diversos planos de la existencia que configuran las realidades vitales de sujetos y colectivos. Juárez (1995: 117) propone una comprensión de la exclusión en la cual se distingue tres zonas: zona de marginación, zona de vulnerabilidad y zona de integración, relacionando condiciones laborales, sociales y de sentido de vida: 
Tabla 1. Zonas de la exclusión

\begin{tabular}{|c|c|c|}
\hline $\begin{array}{c}\text { Zona de } \\
\text { Marginación }\end{array}$ & $\begin{array}{c}\text { Zona de } \\
\text { Vulnerabilidad }\end{array}$ & $\begin{array}{c}\text { Zona de } \\
\text { Integración }\end{array}$ \\
\hline $\begin{array}{c}\text { Exclusión } \\
\text { laboral }\end{array}$ & $\begin{array}{c}\text { Trabajo } \\
\text { precario }\end{array}$ & $\begin{array}{c}\text { Trabajo } \\
\text { estable }\end{array}$ \\
\hline $\begin{array}{c}\text { Aislamiento } \\
\text { social }\end{array}$ & $\begin{array}{c}\text { Relaciones } \\
\text { inestables }\end{array}$ & $\begin{array}{c}\text { Relaciones } \\
\text { sólidas }\end{array}$ \\
\hline $\begin{array}{c}\text { Insignificancia } \\
\text { social }\end{array}$ & $\begin{array}{c}\text { Convicciones } \\
\text { frágiles }\end{array}$ & $\begin{array}{c}\text { Sentido } \\
\text { vital }\end{array}$ \\
\hline
\end{tabular}

Fuente: Juárez 1995.

Lo anterior supone un carácter multidimensional de la exclusión social en la cual se manifiestan aspectos relativos a la distribución de la riqueza y a las desventajas sociales, pero también a la carencia de poder político acompañado de una pérdida de vínculos sociales.

García incluye al concepto de exclusión social las afectaciones en el dinamismo vital y existencial de las personas excluidas:

La exclusión es un modo de identificar a ciertos enclaves territoriales en los que se cristalizan de manera dramática la des-estructuración social, las tasas de desempleo, la ruptura de las solidaridades vecinales, la instalación en la precariedad y la falta de perspectiva (...).

La exclusión se representa también en clave existencial en la medida que afecta a la subjetividad y a la forma de emocionar la realidad. Los procesos de exclusión conocen los sentimientos de impotencia y afectan a los dinamismos vitales. (...). Los excluidos comparten la quiebra de los dinamismos fundamentales del ser vivo: la confianza, la identidad, la reciprocidad, la autoestima (2006: 12).

En este orden de ideas, se definen tres categorías y tres ejes claves para comprender la exclusión social:
Tabla 2. Categorías y ejes de la exclusión

\begin{tabular}{|c|c|}
\hline \multicolumn{2}{|r|}{ EJE POLÍTICO - INSTITUCIONAL } \\
\hline $\begin{array}{c}\text { Categoría } \\
1 \\
\text { Derechos }\end{array}$ & $\begin{array}{l}\text { Dimisión de la responsabilidad } \\
\text { pública. } \\
\text { Fracaso de las políticas sociales, } \\
\text { laborales y educativas. } \\
\text { Fractura de procesos de participación } \\
\text { social. }\end{array}$ \\
\hline \multicolumn{2}{|c|}{ EJE ECONÓMICO - ESTRUCTURAL } \\
\hline $\begin{array}{l}\text { Categoría } \\
2 \\
\text { Inserción } \\
\text { económica }\end{array}$ & $\begin{array}{l}\text { Falta de ingresos, alejamiento del } \\
\text { mercado de trabajo. } \\
\text { Perdida de integración. } \\
\text { Privación de bienes materiales. }\end{array}$ \\
\hline \multicolumn{2}{|r|}{ EJE SOCIAL - RELACIONAL } \\
\hline $\begin{array}{c}\text { Categoría } \\
3 \\
\text { Biografías }\end{array}$ & $\begin{array}{l}\text { Debilitamiento de los dinamismos } \\
\text { vitales que configuran el pulso vital } \\
\text { de las personas. } \\
\text { Quiebre en la subjetividad y en } \\
\text { la intersubjetividad, afectando la } \\
\text { estructura identitaria de los sujetos } \\
\text { y como consecuencia la estructura } \\
\text { identitaria colectiva. } \\
\text { Ruptura de confianzas, reciprocidad, } \\
\text { identidad, autoestima. }\end{array}$ \\
\hline
\end{tabular}

Fuente: elaboración propia a partir de García 2006

La exclusión como proceso de pérdida de integración incluye no solo la falta de ingresos y el alejamiento del mercado de trabajo, sino también un descenso de la participación social y por tanto, la pérdida de derechos sociales. 


\section{La exclusión como proceso}

En este orden de ideas, la exclusión se entiende como un acontecimiento vivencial que afecta a personas y colectivos en el transcurso de su historia y que, por lo mismo, es procesual; que posee un origen estructural, que hunde sus raíces en la forma en que se ha organizado la sociedad, lo que lleva a plantearla como un producto social, esencialmente diverso y heterogéneo y difícil de acotar dada la multidimensionalidad de los factores que contribuyen en la concreción (Rubilar 2013). Incluye también un entramado de relaciones de privación de "múltiples bienes materiales, simbólicos, espirituales y de trascendencia, imprescindibles para el desarrollo autónomo de la identidad esencial y existencial" (Vasilachis 2003: 91).

La exclusión también se manifiesta como desafiliación para indicar la ruptura de las redes familiares, el debilitamiento de las relaciones sociales y la fragilidad de los lazos de proximidad. Ser excluido significa la quiebra de los tejidos que aseguran el subsuelo de la vida humana y aseguran la protección, la confianza y la transmisión de sentido; alude a la desconexión de los dinamismos sociales, de los intercambios productivos y de los procesos de comunicación (García 2006).

En este sentido, se puede hablar de un proceso en dónde confluyen tres factores fundamentales: el sujeto excluido, el entorno de exclusión y las estructuras excluyentes, esta elaboración retoma a García (2006) y Vasilachis (2003).

\section{A continuación se explican estos factores:}

1. El sujeto excluido: tiene que ver con la concepción del sujeto, con las maneras en que desde los centros de poder, se nombra, representa, concibe e interactúa o no con aquellos en situaciones de exclusión. Alude a las miradas y lecturas del otro (excluido) desde las políticas públicas, que dan lugar a discursos e intervenciones institucionales.

2. El entorno de exclusión: hace referencia a las condiciones necesarias y suficientes que explican y dan cuenta de la trayectoria y reproducción de la exclusión y la pobreza. Da cuenta también de los contextos y coyunturas que son artífices de situaciones excluyentes.

3. Las estructuras excluyentes: se entienden como aquellas que provocan desigualdades estructurales, que se encuentran en el sustrato mismo de la sociedad, en las configuraciones económicas, políticas, sociales y culturales de los contextos actuales.

La confluencia de estos factores permite comprender de una manera compleja los fenómenos asociados a la exclusión, no se trata solo de condiciones aisladas de sujetos que habitan enclaves territoriales específicos, se trata también de entornos, coyunturas y estructuras productoras de exclusión a nivel mundial, y su constante normalización dentro de la organización de la sociedad que habitamos.

Bajo esta línea discursiva, la pobreza y la exclusión se inscriben en la trayectoria histórica de las desigualdades sociales que implican fracturas en el tejido social, imposibilitando al sujeto como productor de sentidos para la vida.

Esto es relevante en la medida en que la sociedad pareciera limitar en los sujetos la capacidad de romper el destino, convirtiendo estos fenómenos en algo natural e inevitable, dejando de ser una cuestión ética y política para convertirse en un simple hecho irreversible, 
inherente a las sociedades actuales, la cual es comprendida a partir de la subsidiariedad y abordada desde el asistencialismo.

En este sentido, advierte Bauman, "para quienquiera que fuere una vez excluido y destinado a la basura, no existen sendas evidentes para recuperar la condición de miembro de pleno derecho" (2004: 30).

Algunas representaciones de la exclusión social y la pobreza se han construido sobre metáforas espaciales, para indicar la marginalidad, la producción de la distancia y, en consecuencia, las prácticas de inserción sostenidas por el modelo económico, político, social y cultural. Desde esta perspectiva, la sociedad se ha entendido como un espacio ordenado, que se construye en torno a un centro y a una periferia, a los del centro se les atribuye el poder, y a las periferias, la insignificancia.

Excluidos son los que quedan fuera de las puertas de entrada que conducen, en pleno derecho, a los dinamismos hegemónicos que cohesionan la organización social. Fuera quedan los que no han podido traspasar las puertas de entrada de una sociedad de productores y de consumidores. El trabajo, el consumo, la seguridad y la autonomía individual son los lindes que determinan el dentro y el fuera (García 2006). Sin duda, el origen las estructuras excluyentes encuentra sus raíces en la propia configuración del sistema económico-político global y en su modelo de desarrollo.

\section{Las dimensiones de la exclusión}

A partir de este contexto teórico, surge la pregunta sobre las percepciones, nociones, vivencias e ideas que tienen los jóvenes que viven en condición de exclusión social y pobreza en la ciudad de Medellín (Colombia); la indagación se desarrolló con grupos de jóvenes (hombres y mujeres) entre los 14 y los 28 años, quienes habitan en sectores urbanos marginales de la ciudad; 15 de ellos y ellas víctimas del desplazamiento forzado asociado al conflicto armado colombiano.

Para ello se tomó contacto con diferentes grupos de jóvenes y con ellos se realizaron talleres investigativos, de carácter dialógico, que propiciaron el rescate de su voz y su mirada frente al tema de la pobreza y la exclusión.

Las dimensiones de la exclusión aducen a ámbitos objetivos y subjetivos. La dimensión objetiva se aborda usualmente desde las políticas públicas, para lo cual se realizan mediciones a partir de indicadores asociados a las condiciones objetivas de la exclusión y la desigualdad que utilizan, principalmente, herramientas cuantitativas.

Desde estas mediciones se da cuenta de aspectos relacionados con los bajos ingresos, la línea de pobreza, la tasa de desempleo, los niveles de desnutrición y se han estandarizado modelos como el coeficiente de Gini, el índice de calidad de vida, el índice de desarrollo humano, entre otros. A la fecha, estas herramientas son utilizadas, especialmente en el sector público, para medir la condición económica y social de los grupos excluidos.

Por otra parte, son diversos los estudios que han avanzado en la comprensión cualitativa de la exclusión y la pobreza y que han permitido aproximarse a sus dimensiones subjetivas, indagando sobre percepciones, imaginarios, 
representaciones, aspiraciones, sueños, prioridades.

Cada vez son más frecuentes las entrevistas, los sondeos, los grupos de opinión, las biografías, las historias de vida y otros métodos propios de la antropología, la sociología, el trabajo social y la psicología que buscan establecer cómo se piensa a sí mismo el sujeto, cómo se explica su propia condición y cómo interpreta su experiencia biográfica (Saraví 2009).

Frente a estas formas de comprender y medir las consecuencias de la exclusión y la pobreza, es común encontrar que ambos discursos tienen puntos de desencuentro y que la mirada subjetiva no coincide con las condiciones objetivas de la realidad; más aún "en condiciones objetivas de pobreza, desempleo y bajos ingresos, las personas no suelen sentirse pobres o excluidas" (Saraví et al. 2009: 102)

Con relación a las percepciones y discursos sobre la realidad de pobreza y exclusión, en el desarrollo del trabajo de campo se interrogó por varios temas referidos a la concepción que tienen los jóvenes de tres sectores de la ciudad. Para contextualizar territorialmente el estudio, se presentan a continuación algunos datos sobre Medellín.

\subsection{Características del territorio}

Medellín tiene una población estimada de 2.464.322 habitantes (DANE, 2012), siendo la segunda más poblada del país después de Bogotá. Al interior de la ciudad se establecen divisiones y subdivisiones administrativas de acuerdo a la aglomeración poblacional y a las características urbanas o rurales que presentan susterritorios. Deestamanera, en Medellínexisten
16 comunas urbanas y 5 corregimientos rurales, estas comunas a su vez están conformadas por barrios que corresponden generalmente a una agrupación de viviendas delimitada por sus condiciones físicas, económicas o sociales. La ciudad cuenta con 249 barrios los cuales se organizan administrativamente en siete zonas: 1 Nororiental, 2 Noroccidental, 3 Centroriental, 4 Centroccidental, 5 Suroriental, 6 Suroccidental y 7 Distrito rural.

Las características propias de la ciudad definen el posicionamiento económico y social que Medellín ha alcanzado con respecto a otras ciudades del país, considerándola como pionera en sectores como el textil, la oferta de servicios en las áreas de salud, construcción, turismo de negocios, comunicación y energía eléctrica. No obstante, Medellín también se ubica como una ciudad de contrastes, donde se presentan problemáticas como el desempleo, el empleo informal, el trabajo infantil, el conflicto armado urbano, la recepción y expulsión de población desplazada, la corrupción, entre otras situaciones que agudizan las condiciones de marginalidad y pobreza de sus habitantes.

Los jóvenes, en este caso, no se escapan de estas problemáticas. Según un informe de la CEPAL del 2003, en América Latina y el Caribe la mayoría de las personas pobres tiene menos de 30 años y afrontan graves dificultades en el acceso a los servicios básicos, sobre todo en salud y educación. Allí se indica que a pesar de los esfuerzos desplegados por los gobiernos en los últimos años y de los notables avances obtenidos, principalmente en la cobertura de aquellos servicios, todavía quedan grandes segmentos de esta población a los que los separa una inmensa brecha de las posibilidades de lograr su desarrollo integral y armónico. Todo 
ello amenazaría la estabilidad y la sostenibilidad del desarrollo social de los países de la región.

Las diferencias sociales que proporciona la desigualdad se ve reflejada en los "circuitos de vida" juvenil. Por ejemplo, los sectores de estratos altos y medios (una proporción menor), tienen altos niveles educativos, futuros laborales promisorios, y pueden formar familias estables. Los jóvenes pobres (170 millones de personas jóvenes) en cambio:

\begin{abstract}
Tienen vidas marcadas por la falta de oportunidades. Deben trabajar desde temprana edad, sus posibilidades de cursar estudios primarios y secundarios son limitadas, tienen riesgos significativos en salud, no tienen red de relaciones sociales que pueda impulsarlos, no hay crédito para ellos, su inserción laboral es muy problemática, difícilmente logran quebrar la situación de privación de sus familias de origen (Kliksberg 2011: 11).
\end{abstract}

En Medellín, la situación de los jóvenes no es distinta a la planteada: el desempleo, por ejemplo, se agudiza aún más en este tipo de población ${ }^{4}$, que para el año 2013 había alcanzado un 17,6\%, de acuerdo a cifras del Informe de Calidad de Vida del programa Medellín Cómo Vamos.

A lo anterior se suma que de aquellos jóvenes que se nombran como ocupados, se ubican los trabajadores informales, que según estudios de la ONG local Escuela Nacional Sindical, es una categoría que resume la mayor forma de precarización laboral:

Son invisibles, están integrados al paisaje, nadie los ve, o nadie quiere verlos. Pero ahí están: en las calles y en las esquinas, en los buses, en los talleres y las cocinas; concentrados en los centros de las ciudades o de puerta en puerta en cada barrio; esquivando el rechazo y la indiferencia; guerreando por las monedas para su sustento (Vélez 2013).

Esta cifra es significativa porque la población juvenil entre los 15 y 29 años representa el $23,35 \%$ del total de habitantes de la ciudad (DANE, 2010).
De los 566.875 jóvenes habitantes de Medellín, aproximadamente el $20 \%$ se encuentra en condiciones de pobreza (DANE, 2012), lo que significa que su circuito de vida está caracterizado por una serie de dificultades que limita no solo el acceso al empleo digno sino también a otros bienes culturales, de salud, educación, recreación y deporte, que los excluye de la vinculación y la participación de niveles mínimos de bienestar.

\subsection{Características de los jóvenes que participaron en el estudio}

Con el fin de realizar un acercamiento a las realidades juveniles en el marco de las intencionalidades del proyecto de investigación: "Estrategias de sobrevivencia de los jóvenes en condiciones de pobreza de la ciudad de Medellín"; se contó con la participación de 84 jóvenes, habitantes de la ciudad y, en una proporción menor provenientes de otros municipios del Área Metropolitana como Bello y Envigado.

Los jóvenes que participaron del proceso de investigación se contactaron a partir de su vinculación a organizaciones comunitarias y/o entidades de carácter público y privada de las diferentes comunas de Medellín, los grupos juveniles que se articularon de manera voluntaria fueron: "Dejando Huellas", "Movimiento Cultural Juvenil", el Centro de Desarrollo Cultural de Moravia y jóvenes que estaban cursando una Diplomatura organizada por la Fundación Universitaria Luis Amigó 5 .

\footnotetext{
La Fundación Universitaria Luis Amigó en convenio con la Multinacional Diageo Colombia S.A., convocó a jóvenes de estratos socioeconómicos bajos para la formación gratuita en una diplomatura en Bartender, servicio de mesa, bar y coctelería e Impulso de marcas, ventas y servicio al cliente. Durante el desarrollo de la diplomatura desde el proyecto de investigación se extendió la invitación a un grupo de jóvenes para que hicieran parte del estudio.
} 
Con respecto al sexo y al rango de edad se identifica que de los 84 jóvenes participantes, el $50,03 \%$ pertenece al sexo masculino y el $49,97 \%$ al femenino. Las edades, se concentran mayoritariamente entre los 19 y 23 años $(51,6 \%)$; también existe una proporción (19,3\%) entre los 14 y 18 años. Un 16,3\% de los participantes está dentro de los 24 y 28 años. Mientras que los porcentajes más bajos se encuentran entre los que tienen menos de 14 años y más de 28 años $(1,5 \%$ y $0,1 \%$, respectivamente). Estos datos permiten afirmar que los jóvenes que participaron de los talleres se encuentran entre los 14 y 28 años, lo cual representa el $87,2 \%$ del total.

Sobre lo anterior, se plantean dos precisiones. Para los estudios socioeconómicos es importante la variable "sexo" ya que determina lo que representa la pobreza para ambos sexos. En las mujeres, por ejemplo, se agudiza la precarización laboral y el desempleo y para los hombres la problemática de la deserción escolar y la delincuencia juvenil es más notoria y preocupante. Los porcentajes entre las mujeres y hombres para este estudio son similares, lo que permitió recuperar las percepciones de los jóvenes a nivel general y enriquecer el ejercicio investigativo.

Ahora bien, con respecto a lo segundo, en Colombia la Ley Nacional de Juventud 375 de 1997, cataloga como joven a los hombres y mujeres entre 14 y 26 años y según el Acuerdo 019 de 2014 emitido por el Concejo de Medellín el rango se encuentra entre los 14 y 28 años. El enfoque demográfico define a la juventud dentro de un rango etario y hace énfasis en los procesos claves del ciclo vital que marcarían las fronteras con las demás etapas (niñez, adultez, vejez). No obstante, esta mirada invisibiliza posturas teóricas dentro de la sociología y la ciencia política que plantean que la juventud es una condición social que hace parte de la complejización de la sociedad y que depende de dos factores: lo que el joven piensa y siente acerca de sí mismo, y lo que el mundo de los adultos piensa y siente acerca de este joven en una época determinada.

Con respeto al nivel de escolaridad se evidencia que existe un porcentaje significativo de jóvenes que han alcanzado estudios técnicos $(28,49 \%)$, mientras que el $22,13 \%$ dice que ha estudiado hasta la secundaría. Llama la atención que aún existan jóvenes que tienen la primaria incompleta, es decir, el $0,76 \%$ y solo el $1,51 \%$ estudios universitarios incompletos.

A la pregunta ¿Estudia Actualmente? la mayoría de los jóvenes señala que sí, es decir, el $65,80 \%$; mientas que un $9,08 \%$ dice que no. Aunque este dato ocupa un porcentaje menor con respecto a la mayoría, es importante advertir que existen jóvenes entre los 14 y 28 años que en la actualidad no realizan ningún tipo estudio. Con respecto al tipo de estudio, el $65,80 \%$ de jóvenes que manifestó estar estudiando, el $36,13 \%$ dice que actualmente hace un diplomado, $13,67 \%$ realiza una técnica y el $8,12 \%$ está cursando secundaría.

Las cifras anteriores muestran un panorama de la precariedad educativa de estos jóvenes que aún no terminan estudios superiores (algunos no tienen la educación básica completa) y se concentran en formación técnica para un mercado laboral que no les ofrece mayores expectativas laborales y de ingresos. Sin duda, dentro de los estudios sobre la pobreza lo educativo es un factor de riesgo social que agudiza las condiciones de exclusión de 
los jóvenes, por lo general esta variable es condicional para entender los bajos niveles de ingresos que devenga esta población y la precarización laboral a la que están sometidos.

El encuentro con 84 jóvenes procedentes de diferentes barrios de la ciudad, permitió reconocer como primera característica que una parte de ellos (15 jóvenes) son víctimas del desplazamiento forzado de regiones de Antioquia como Occidente, Norte y Urabá y de otros lugares del resto del país como Córdoba y Montería 6 .

En sus historias de vida se evidencia las huellas que deja el conflicto armado en el país; obligados a salir de manera involuntaria de sus territorios de origen, los jóvenes y sus familias llegan a la ciudad con la intención de conseguir un lugar para vivir. En los siguientes testimonios se identifica lo anterior:

"El 27 de febrero de 2007 mi papá y mi mamá murieron, los mataron los "paracos" en Santa Rosa de Osos, después nos tocó irnos a vivir a otro lugar, nos tocó hacer nuestra propia casa y desde ahí vivo con mi abuela" ${ }^{7}$

"Yo nací aquí en Medellín pero me crie en Cañas Gordas en un pueblo que queda a cuatro horas de Medellín, yo me crie con mi abuela hasta los cinco años, de allá salimos como desplazados y llegué a este barrio, nosotros llegamos a una casa que alquilaron y ya aquí me terminé de criar"8

\footnotetext{
Informantes claves grupo Esfuerzos de Paz II, comunicación personal, 17 de febrero, 2015.

Joven de 20 años

8 Joven de 19 años
}

De entrada, la condición de víctima, los ubica en un lugar de desventaja, dado que la gran mayoría llega a Medellín a poblar los cordones de miseria que se encuentran en las laderas de la ciudad. Esta situación no es distinta para muchas de las familias que aunque no son desplazadas de la violencia enfrentan la sobrevivencia del día a día al no tener recursos necesarios para vivir con dignidad.

Las comunas en las cuales viven los jóvenes presentan precariedad en las condiciones de habitabilidad familiar, por ejemplo, la utilización de materiales de desecho y residuos sólidos para la construcción de las viviendas, la ubicación en laderas o lugares no aptos debido a la inestabilidad del suelo, la escasa y deficiente infraestructura social y comunitaria y el acceso limitado de los servicios públicos domiciliarios, son algunas de las características que denotan la pobreza en los jóvenes de la ciudad.

Con respecto a la afiliación al sistema de salud, que es un indicador de calidad de vida, se encontró que existe un grupo de jóvenes que representa el 50,06\% que pertenece al régimen subsidiario o EPS $^{9}$ (bien sea como contribuyente o como beneficiario). También se observa en un porcentaje menor, que existen jóvenes que manifiestan que en el momento no tienen garantizado este derecho. Este último dato genera preocupación porque la salud se constituye en un derecho fundamental de todo ciudadano según está consignado en la Constitución Política de Colombia.

En relación con el aspecto económico, un número significativo de jóvenes realiza algún tipo de actividad que le genera ingresos, es decir,

\footnotetext{
Entidad Prestadora de Salud
} 
el 42,55\%. Del total de jóvenes que señalaron realizar algún tipo de actividad económica, el $17,03 \%$ expresa que se dedica al área de las ventas (ropa, accesorios), es decir, el 17,03\%; el $10,36 \%$ se dedica a labores varias como: auxiliar de almacén, instalador de ascensores, lavado de carros y negocio de internet. También existen jóvenes que se desempeñan en actividades culturales y artísticas y en el negocio de comidas rápidas $(5,38 \%, 4,20 \%$, respectivamente).

Estos datos permiten afirmar que los jóvenes se valen de diversas estrategias de sobrevivencia para hacerle frente a las necesidades y demandas cotidianas personales y familiares, las cuales se pueden desarrollar de manera esporádica (por temporadas) o permanente. Como se evidencia en las cifras presentadas estos jóvenes tienen muy pocas posibilidades de aspirar a empleos formales que les genere estabilidad e ingresos necesarios para superar las condiciones de pobreza en las que se encuentran. El nivel de educación que han alcanzado y el tipo de formación que actualmente realizan está directamente relacionado con un mercado laboral que demanda la ocupación de perfiles técnicos para el desarrollo de funciones con ingresos que no superan el salario mínimo legal establecido.

\section{3. ¿Qué piensan los jóvenes sobre la pobreza y la exclusión?}

Con los jóvenes que participaron en la investigación se reflexionó sobre las manifestaciones de la pobreza en aspectos como: educación, alimentación, salud, trabajo, aspecto espiritual y familiar.

Las dimensiones a partir de las cuales se agruparon los datos de la investigación fueron construidas retomando los referentes teóricos que orientaron el estudio, pero éstas también fueron emergiendo a partir de la interacción que se tuvo con los jóvenes participantes. Es decir, las posturas teóricas y conceptuales sobre la pobreza y la exclusión permitieron definir preguntas orientadoras y problematizadoras que fueron incluidas en los instrumentos utilizados para recoger la información, pero al mismo tiempo, estas intenciones de indagación fueron contrastadas y reflexionadas a partir de la información que emergió en el trabajo de campo y en general en el proceso investigativo; dando un lugar protagónico a las perspectivas de los jóvenes en este análisis. En cada una de estas dimensiones se rescatan expresiones de los participantes relacionadas con sus vivencias personales y familiares.

Se definieron entonces seis dimensiones de comprensión desde los elementos reflexivos de los jóvenes participantes:

- Dimensión espiritual-personal

- Dimensión familiar

- Dimensión alimentaria

- Dimensión trabajo

- Dimensión salud

- Dimensión educación

Con respecto a la dimensión espiritualpersonal, los jóvenes señalan la falta de emprendimiento e iniciativa como un aspecto relacionado con la pobreza del espíritu, mencionan también la desconfianza en sí mismo, el miedo y evidencian "la pereza y el desgano", como características personales y actitudinales que influyen y configuran vivencias relacionadas con el mundo de las necesidades básicas insatisfechas. De igual forma, es relevante para ellos que las características de 
cada persona definen una actitud que puede favorecer la pobreza y la exclusión, toda vez que limita las acciones que se puedan emprender en situaciones de necesidad y carencia material. Al respecto mencionan aspectos como:

"Hay pobreza por falta de ser guerrero y no tener un motivo para poder emprender"10

"Es pobre de espíritu porque no piensa por sí mismo, se deja llevar"11

"Porque hay personas que no les gusta superarse, son muy negativas, no piensan en un futuro" 12

En este sentido, es interesante la narración de los jóvenes en cuanto perciben áreas de la exclusión relacionadas con las subjetividades, con las construcciones propias de cada persona y de la manera en que se ubican y actúan en el mundo. Esta relación con las biografías que se planteó en la discusión teórica es relevante para los jóvenes en tanto los habilita o inhabilita para asumir o enfrentar las diversas situaciones que el proceso de exclusión despliega en la realidad; de esta manera los quiebres en la subjetividad generan rupturas en la autoestima, la confianza, la identidad, la reciprocidad, la cooperación, la solidaridad.

Como consecuencia de ello, los jóvenes de sectores excluidos manifiestan una suerte de indiferencia frente al futuro, una especie de desesperanza frente a un posible cambio de vida. Las características de los entornos en los cuales se desenvuelven los jóvenes y la forma en que ellos los interpretan, parecieran

Joven de 15 años.

11 Joven de 14 años.

12 Joven de 19 años. normalizar un destino, una imposibilidad de romper con una forma de vida a la cual se han acostumbrado y que se reproduce de manera cotidiana.

Esta lectura que hacen los jóvenes sobre su realidad de pobreza y exclusión y la responsabilidad que tiene cada persona en ella, está muchas veces desprovista de una reflexión sobre las estructuras excluyentes, aquellas que producen desigualdades estructurales y que se configuran en los contextos económicos, políticos y culturales.

"La pobreza es por resignación en los jóvenes, se quedan en una esquina, hay gente que se queda ahí toda la vida, esperando lo que me dé la vida (...) si la vida me da bien, si no me da también"13

"Para mí una persona pobre es la que se queja, la perezosa, la mal vestida, que le gusta que la gente la vea mal, que no busca soluciones que mejoren su calidad de vida sino que se vuelven facilistas y acostumbrados"14

"Para mí una persona pobre no es la que le falta el dinero sino aquel ser humano que está vacío por dentro, que todo le da igual, que nada le parece bien, que se queja por todo, que siempre está mirando el lado negativo de las cosas, que todo le molesta, que no tiene una sonrisa en el rostro (...) Una persona pobre es la que no sueña, que es conformista, que no tiene actitud, que no es visionaria, que todo le da igual"15

\footnotetext{
Joven de 15 años

Joven de 20 años

5 Joven de 24 años
} 
"Para mí la pobreza va más allá de lo material, es ser pobre de espíritu y siempre pensar en negativo (...). Uno nunca debe ser negativo recuerda que la mente siempre traerá todo lo que queramos, quizás algunos dirán un pobre es el que vive en un "rancho", no tiene comida u otras cosas; pienso que no hay nadie pobre simplemente que son pobres espiritualmente y mentalmente"16

Desde la perspectiva de los jóvenes existe una responsabilidad personal al ser o considerarse pobre, es decir, las características del sujeto tienen una incidencia directa en las condiciones materiales que se observan en la realidad. Si bien evidencian unos aspectos de la pobreza que pueden ser objetivados en lo real como el acceso a servicios públicos, las condiciones de la vivienda, la alimentación, el empleo, los ingresos; para ellos hay otras condiciones subjetivas que son las que propician el ser pobre, a las cuales les otorgan gran relevancia, incluso al momento de definir estrategias de sobrevivencia.

Por su parte, la dimensión espiritual de la pobreza para los jóvenes está relacionada con las creencias religiosas y con la fe, también con valores ciudadanos y con las decisiones que las personas toman con base en sus principios de vida.

"Una persona es pobre espiritual y moralmente cuando le falta a los principios de la sociedad o sea uno como ser humano perjudicar a los demás"17

"Somos pobres cuando dejamos de creer, cuando desechamos lo importante para nuestras vidas, lo que nos ayuda a crecer y a entender lo valioso que es vivir"18

\section{"Una persona que no cree en Dios"19}

"Pobreza espiritual: sin creencias, sin motivaciones de salir adelante, metido en la drogadicción, en la prostitución, en no saber tomar decisiones, en propuestas negativas como vender drogas, entrar a organizaciones de delincuencia, incluso robar"20

"Aunque uno a veces relaciona pobreza con lo económico, para mí no está bien describirse así como una persona pobre, solo en ocasiones tenemos iliquidez económica y ya, lo que no quiere decir que seamos pobres. Pobre es quien no valora el tener vida y salud porque desde que hayan estas podemos salir adelante, ya que lo económico y lo material no es lo más importante"21

Lo espiritual asociado a las condiciones de pobreza incluye para ellos la toma de decisiones de vida que pueden desembocar en situaciones de riesgo como la delincuencia, el consumo de sustancias psicoactivas e incluso en hacer parte de grupos al margen de la ley presentes en los barrios periféricos de la ciudad. Estas circunstancias son nombradas por los jóvenes como opciones que algunas personas toman cuando se es pobre de espíritu.

Con respecto a la dimensión familiar los jóvenes asocian la exclusión y la pobreza con aspectos de la dinámica interna como el

\footnotetext{
Joven de 16 años

19 Joven de 14 años

20 Joven de 18 años

21 Joven de 23 años
} 
apoyo, la afectividad y la cohesión, toda vez que se lee entre en sus frases sentimientos de inconformidad frente al trato que reciben de sus padres, madres, adultos cercanos y familiares.

En este sentido, la pobreza sería interpretada por los jóvenes por una dimensión que tiene que ver con las relaciones interpersonales, una persona pobre en la familia, por ejemplo, es aquella que no cuenta con apoyo, que no recibe afecto y en la cual sus integrantes no son unidos ni han construido valores desde el respeto y la solidaridad.

"Jóvenes que carecen de apoyo familiar (...) y apoyo en sus hogares y sus vidas. Personas pobres de afecto que caen en las drogas y alcohol" 22

"Una persona pobre no tiene un hogar digno, no tiene forma de estudiar, de tener su diario (comida), la que le toca mendigar, la que no tuvo la oportunidad de trabajar, de aprender"23

"Jóvenes con falta de espiritualidad y de valores en la familia, porque si no tiene esos dos pilares en su vida, puede hacer cosas que no le convengan"24

Desde la perspectiva de la población juvenil que participó en la investigación, se establece una relación entre los valores que se aprenden en la familia y la posibilidad de llegar a situaciones de riesgo que se presentan en el contexto específico de los barrios marginales de la ciudad de Medellín. Unido a esta percepción, los jóvenes reconocen la importancia de contar con lazos familiares y redes de apoyo que

\footnotetext{
Joven de 17 años

Joven de 16 años

24 Joven de 20 años
}

soporten de alguna manera las demandas que la situación diaria les plantea.

Retomando las zonas de la exclusión nombradas en apartados anteriores de este artículo, es posible relacionar esta idea de pobreza en la familia con lo que Juárez denomina las zonas de marginación y vulnerabilidad en las que se puede encontrar una persona excluida, resaltando categorías como las relaciones inestables, las convicciones frágiles, el aislamiento y la insignificancia social que puede experimentar un sujeto en situación de exclusión; en contraposición a la presencia de relaciones sólidas y de un sentido vital asociado a una zona de integración.

En este sentido, el aspecto existencial de la exclusión, tiene que ver también con la forma de emocionar y reaccionar ante la realidad. La pérdida de sentido vital y las rupturas con los dinamismos fundamentales del ser vivo (García 2006) son nombradas por los jóvenes cuando mencionan la falta de autoestima, el desgano, la falta de apoyo, el no sentirse protegido, apoyado y cuidado por su círculo familiar y social inmediato.

La dimensión alimentaria, los jóvenes la relacionan con un asunto primordialmente económico, es decir, que la falta de ingresos en la familia restringe las posibilidades de alimentarse. De igual forma, aluden que la falta de alimentos en el hogar está relacionada con la imposibilidad de comer, por lo menos, tres comidas diarias.

"Es muy caro comer (...) Siempre uno come lo mismo: papa, arroz, huevo" 25

\footnotetext{
Joven de 20 años
} 
"Se es pobre cuando tiene que ir a pedir para poder tener que darle de comer a sus hijos"26

"Cuando una persona solo come una vez al día"27

Otro aspecto es la relación que establecen entre tener hábitos alimenticios poco saludables como un factor que define condiciones de pobreza en una persona.

Es de resaltar que en los talleres realizados con los grupos de jóvenes se evidenció que dentro de sus hábitos alimentarios, muy pocos consumen verduras, frutas y ensaladas de manera regular, en cambio un alto consumo de carbohidratos como arroz y papa; además muy pocos incluyen de manera diaria proteínas como la carne de res y cerdo, el pollo, el pescado, ante lo cual manifiestan: "cuando hay para comer carne comemos y cuando no hay, comemos otras cosas"28.

Algunos jóvenes coinciden en afirmar que no tienen buenos hábitos alimenticios y que esto se debe a la falta de interés y a la facilidad que da el comer alimentos fritos o comida "chatarra". Al respecto los jóvenes plantean:

"Uno no lleva una buena alimentación porque uno es muy facilista, uno come muchos fritos"29

"Cuando le da pereza a la hora de cocinar alimentos saludables, todo frito sale más rápido"30

Joven de 20 años.

27 Joven de 13 años.

28 Joven de 24 años

29 Joven de 19 años

30 Joven de 22 años.
En el análisis de la información también aparece como estrategia para la alimentación el "recorrido", la cual es utilizada por las familias para hacerle frente a la escasez de alimentos en el hogar. Consiste en recorrer un territorio cercano y pedir comida de casa en casa, acudiendo a la solidaridad de los vecinos para complementar los alimentos del día. Frente a esta práctica los jóvenes nombran sentimientos de humillación, desconsuelo, tristeza, desesperanza y frustración; nombran que es una práctica a la que acuden en momentos de gran escasez. Algunos testimonios asociados a este tema son:

\footnotetext{
"Veo ahora a los niños pidiendo comida y me recuerdan cuando yo tenía que hacer el "recorrido" para pedir alimentos, mucha gente le decía a uno trabaje en lugar de pedir, pero no hay donde, uno pide por necesidad y es mejor pedir que robar." ${ }^{31}$

"Los niños pidiendo comida y sin haber, las condiciones son muy difíciles, se ve mucha pobreza y no se tiene la plata para comprar la comida"32

Las condiciones precarias para poder alimentarse además de tener una incidencia en las condiciones físicas (desnutrición) de los jóvenes, también inciden en el quiebre de los dinamismos vitales, afectando la subjetividad.

La inserción económica como categoría de análisis de la exclusión que tiene que ver con la falta de ingresos y la privación de bienes materiales, en esta dimensión, se relaciona con una categoría social-relacional, pues se constituye en un acontecimiento vivencial que afecta al joven en su historia personal y familiar y en su configuración identitaria.
}

Sobre la dimensión del trabajo, los jóvenes señalan que es una problemática que se presenta por falta de educación, describen como el bajo nivel educativo afecta las posibilidades de encontrar un empleo digno y tener una remuneración acorde con sus necesidades.

\footnotetext{
Joven de 18 años

32 Joven de 20 años
} 
"Por no haber estudio o porque sus padres no les dieron un buen estudio"33

Aparece en este sentido como un aspecto recurrente en sus relatos el tema económico como un detonante que acentúa condiciones de pobreza y exclusión, el aspecto económico lo relacionan con bajos ingresos, condiciones de empleo poco dignas y desempleo, lo cual complejiza el acceso a sus derechos y limita el desarrollo de sus capacidades de desarrollo. La precarización del empleo también aparece en sus relatos:

"Hay mucho empleo pero muy mal remunerado, no pagan prestaciones" 34

"Es que quieren abusar de las necesidades de las personas que necesitan darle de comer a sus hijos y les pagan cualquier peso por cosas que deberían pagar más"35

"El trabajo es muy mal remunerado y cada año todo sube, suben el salario mínimo pero todo sube el triple" 36

De igual forma, los jóvenes consideran que las condiciones físicas y sociales de las personas pueden constituirse en un factor que afecta las posibilidades de empleo, como la edad o la experiencia laboral.

"No me contratan por tener tatuajes"37

\footnotetext{
Joven de 14 años

4 Joven de 21 años

Joven de 19 años

Joven de 22 años

37 Joven de 18 años
}

"Uno muchas veces tiene un estudio pero si no tiene experiencia entonces no sirve, entonces mire que muchas veces uno tiene el conocimiento, pero entonces como no tiene una experiencia laboral en lo que estudió, no tiene oportunidad." 38

"Y es irónico porque ¿una persona bien joven como va a tener 5 años de experiencia?, ¿de dónde? si acabamos de salir de la universidad"39

Evidencian también como un tema recurrente para ellos la discriminación que afecta a personas que habitan ciertos barrios de la ciudad, quienes son excluidos de ofertas de empleo debido a su lugar de residencia y el estigma que se genera en ciertos enclaves territoriales.

De manera general, las características que los jóvenes mencionan alrededor de la pobreza en la dimensión del trabajo tienen que ver con las condiciones educativas, las escasas oportunidades laborales, la baja remuneración y condiciones de empleabilidad poco dignas, la discriminación por la edad, por falta de experiencia y por la procedencia.

Con respecto a la dimensión de la salud, los jóvenes expresan como un asunto crítico la falta de afiliación al sistema de salud, ya sea público o privado. También se identifica que los bajos ingresos y las pésimas condiciones en la atención y la infraestructura hospitalaria, se presentan con más recurrencia cuando las personas son pobres y no tiene los recursos económicos necesarios para acceder a una atención de calidad.

\footnotetext{
Joven de 25 años

Joven de 26 años
} 
"La gente pobre no tiene salud porque no tiene plata para los medicamentos" 40

"Cuando alguien se enferma, la familia no tiene los recursos para llevar a una persona a un hospital"41

Son recurrentes en los testimonios de los jóvenes las críticas al Sistema General de Salud del país, en donde nombran temas como la falta de medicamentos, las largas esperas para acceder a una cita médica o con un especialista de la salud y la negligencia en la atención hospitalaria. Al respecto plantean:

"Hay hospitales que no tienen recursos para atender a la gente" 42

"Cuando no tienen buena atención. Cuando el centro de salud más cercano no tiene las urgencias o doctores. Cuando no hay suficientes medicamentos" 43

"Falta más medicamentos, más atención para personas mayores y que no le den tanta importancia al dinero" 44

"Mala atención, falta de medicamentos, medicamentos muy costosos (...) La solución sería que el gobierno ponga de su parte y entienda que las personas no tienen el nivel económico para pagar" 45

Joven de 24 años.

Joven de 20 años

Joven de 22 años

Joven de 23 años

44 Joven de 20 años

45 Joven de 20 años
Por último, en la dimensión de la educación, los jóvenes consideran que el aspecto económico es un factor que limita el acceso a la educación, de igual forma se evidencia que el analfabetismo y los bajos niveles educativos contribuyen a la pobreza.

"La pobreza está en la educación. No hay comida, no hay estudio, no hay nada, nos da por delinquir, la pobreza nos da ganas de robar. ¿Quién dijo que los pobres tienen trabajo digno?"46

"No se puede estudiar porque muchas veces no se tiene plata para ir al colegio, ni para el uniforme, ni para la escuela" 47

Los descriptores de la pobreza desde la dimensión de la educación se refieren a: los ingresos familiares y el empleo propio o de los padres que pueda solventar los costos de la educación, también los jóvenes nombran la calidad del sistema educativo como un factor que genera brechas entre la educación pública y la privada.

"En mi caso es muy difícil, casi no hay universidades públicas (más económicas) y en el barrio mío es muy difícil, yo quiero estudiar administración de empresas o derecho, pero no tengo cómo pagarlo" 48

"Se presentan los malos pagos a los profesores, por eso es que ahí vienen los paros y los perjudicados somos los estudiantes de los colegios públicos" 49

\footnotetext{
Joven de 24 años

47 Joven de 17 años.

48 Joven de 23 años

49 Joven de 15 años
} 
Aluden los jóvenes también a la pobreza educativa cuando no tienen acceso a espacios para desarrollar sus capacidades y destrezas, además mencionan que muchos jóvenes no tienen interés en estudiar y prefieren prácticas delictivas que les generen dinero fácil y rápido.

"Hay problema en educación cuando nosotros tenemos las oportunidades y nos las aprovechamos"50

El acceso a la educación contiene para los jóvenes una noción de lo político, al reconocer que hace falta que las personas luchen por sus derechos y sean conscientes de su importancia dentro de un contexto de precariedad como en el que viven. Al respecto expresan:

"Somos pobres cuando nos niegan nuestros derechos" 51

\section{"Cuando no sabemos defender los derechos"52}

Las interpretaciones de los jóvenes sobre las condiciones educativas abarcan diferentes ámbitos desde el sistema educativo público, hasta las condiciones materiales y económicas para acceder a las instituciones de educación básica y superior, hacen énfasis también en cómo las características de las personas pueden interferir en los proceso de formación como la falta de interés y el no considerar la educación como una estrategia de sobrevivencia en sí misma, toda vez que pudiese facilitarles el acceso a un mercado laboral formal; sin embargo el contexto de precariedad material en algunos casos, les plantea la necesidad de

\footnotetext{
Joven de 16 años

51 Joven de 20 años.

52 Joven de 25 años.
}

empezar a ganar dinero rápido sin tener que invertir años en formarse académicamente. Un último aspecto que resaltan en esta dimensión es la reproducción de los patrones e historias de vida de sus padres, las cuales parecieran reproducirse en el ciclo de la pobreza y la exclusión.

De acuerdo a lo presentado, se encuentra una mirada de los jóvenes, en la cual aparece como una constante el tema económico como un detonante que acentúa sus condiciones de pobreza. Es así como, la alimentación y el acceso a servicios de educación y salud, tienen una relación directa con el nivel de ingresos y las condiciones de empleo.

Sin embargo, también se expresa en sus relatos, que la pobreza no es interpretada como una cuestión exclusivamente material, también abarca una dimensión que tiene que ver con las relaciones interpersonales y familiares como el apoyo, la afectividad y la cohesión. Por otro lado, para ellos, las características o rasgos culturales de cada persona definen una actitud que puede favorecer la pobreza, toda vez que limita las acciones que se puedan emprender en situaciones de necesidad y carencia material.

\section{Conclusiones}

En este apartado de conclusiones señalamos las cuestiones más importantes que han constituido el desarrollo argumental de la delimitación conceptual de pobreza y exclusión social y su incidencia en la población juvenil, a partir de los análisis realizados con los participantes de la investigación. Iniciamos el artículo realizando una aportación sobre las características que ayudan a delimitar con mayor precisión los 
conceptos de pobreza y exclusión social, entre ellas su multidimensionalidad y su carácter estructural, dinámico e histórico. A partir de algunas de estas características hemos planteado que ambos conceptos requieren ser analizados y comprendidos más allá de su perspectiva clásica y desprovista de una postura política clara, en ese sentido, entendiendo estos fenómenos no solo desde su dimensión económica.

Siguiendo con la temática, hemos especificado la exclusión social como proceso, en el cual confluyen tres factores: el sujeto, el entorno y las estructuras excluyentes; a partir de lo cual se introduce una mirada compleja del fenómeno, que permite incorporar a los análisis, los dinamismos propios del contexto juvenil urbano en territorios marginales. Por último, se han planteado las dimensiones de la exclusión y la pobreza explicitando aquellas que son objetivas y las que son subjetivas. Esta reflexión se articuló a los análisis realizados a partir de lo expresado por los participantes en el ejercicio investigativo realizado con 84 jóvenes en condición de pobreza de la ciudad de Medellín.

Las dimensiones de la pobreza y la exclusión constituyen situaciones claramente observables en la mayoría de las ciudades latinoamericanas, siendo los sectores periféricos y populares los que mayormente han padecido condiciones de vida precarias. Actualmente estas condiciones se vienen amplificado, se han acrecentado las desigualdades y han emergido nuevas formas y manifestaciones de la exclusión social, debido, principalmente, al sistema económico y político mundial.

Las dimensiones objetivas de la pobreza contrastan con una perspectiva de los jóvenes que normaliza y naturaliza las condiciones de exclusión social que viven en su cotidianidad. Los jóvenes no se sienten pobres e incluso plantean diferencias entre ellos y ellas y las personas que, a su modo de ver, si lo son, al respecto expresan por ejemplo: "pobres son quienes no tienen una casa donde vivir o que comer" 53

"Que no tenga absolutamente nada, estar en la calle aguantando hambre" 54

"Para mí la pobreza son aquellas personas que tienen sus casas a orillas de la quebrada, carecen de servicios públicos, comida, sentimientos morales de estudios, buena ropa, salud y de oportunidades de trabajo" 55

"Personas con recursos insuficientes para subsistir día a día, sin techo, sin comida, y sin vestir"56

"Una persona pobre no tiene oportunidades de estudio y de trabajo para salir adelante. No tiene salud. Vive en unas condiciones fuera de alcance. No tiene acceso a los servicios públicos" $" 57$

El caso de las trayectorias económicas, familiares y sociales de los jóvenes describen una realidad en donde se plantea que no todos los sujetos tienen la misma libertad para moverse y actuar. Sus espacios de vida cotidiana en barrios o sectores pobres ubicados

\footnotetext{
Joven de 16 años.

54 Joven de 16 años

55 Joven de 19 años

56 Joven de 18 años

57 Joven de 21 años
} 
algunos en la periferia de la ciudad, limitan el despliegue de prácticas y el planteamiento de nuevos horizontes de reflexión sobre su condición de joven y de ciudadano. Sumidos en el día a día, en la sobrevivencia que implica el no tener garantizado sus derechos económicos, sociales y políticos, restringe en todo caso la construcción de subjetividades políticas que movilicen y cuestionen el sistema económico imperante que los somete a condiciones de pauperización social, económica y política.

Lo anterior propone una línea interpretativa en la cual los dispositivos de poder que instala el modelo económico y político imperante pareciera limitar en los sujetos la capacidad de romper el destino, convirtiendo la exclusión en algo natural e inevitable, dejando de ser una cuestión política para convertirse en un simple hecho irreversible.

Los procesos de globalización y la aplicación de políticas neoliberales han transformado profundamente los modos de ser, pensar y actuar, instalando, incluso, paradigmas que inciden en los sistemas axiológicos de los sujetos. Los jóvenes no se encuentran al margen de estos procesos de alienación, los cuales afectan significativamente sus trayectorias de vida.

Al ser una construcción histórica y social, la juventud se configura y transforma a partir de la forma en que la conciben la sociedad y los propios jóvenes. En este sentido, es posible afirmar que, actualmente los mecanismos de integración social como la familia, la educación y el trabajo se encuentran debilitados en la juventud pobre. Existen problemas para su inserción laboral, teniendo como consecuencia precariedad en el empleo y desocupación; condiciones críticas en la garantía de derechos asociados a la educación y a la salud y una desintegración del ámbito político y participativo, lo cual obstaculiza e impide el ejercicio pleno de la ciudadanía.

Desde una perspectiva general, entre los diferentes colectivos sociales que se hallan en mayor condición de exclusión y pobreza se encuentran los jóvenes, quienes se encuentran expuestos a las transformaciones de la estructura económica y social y de las políticas del Estado frente a la sociedad, las cuales generan marcadas desigualdades en sus condiciones de vida.

Prevalece una idea de no futuro, una necesidad de resolver la sobrevivencia diaria, una perspectiva de vida donde los sueños no tienen lugar, en cambio, la precariedad, la discriminación, la carencia, el aislamiento y la desesperanza, parecen transversalizar el imaginario de los jóvenes pobres y excluidos.

Estas dimensiones, que objetivan condiciones y consecuencias en trayectorias vitales juveniles marcadas por la pobreza y la exclusión, exigen procesos de investigación y actuación interdisciplinar, que reflexionen crítica y multidimensionalmente el problema; reconociendo que la pobreza, exige análisis que vayan más allá de los indicadores de renta e ingresos y que las posibilidades de futuro son, en sus imaginarios, cada vez más escasas. 


\section{Bibliografía}

Álvarez, L; Bernal, J. y Sepúlveda, D. 2011. Exclusión social en Medellín: sus dimensiones objetivas y subjetivas. Estudios Políticos, 39: 97-116.

Bauman, Z. 2004. Vidas desperdiciadas. La modernidad y sus parias. Barcelona: Paidós.

Castillo, H. 2008, Los jóvenes populares ¿cuál futuro? Acerca del papel de la organización de los jóvenes y de las políticas juveniles. En Cordera, R. Kuri, R. Ziccardi, A. (Coord.) Pobreza, desigualdad y exclusión social en la ciudad del siglo XXI. México: Siglo XXI.

Consejo Latinoamericano de Ciencias Sociales - CLACSO. 2009. Pobreza: Un glosario internacional. Edición literaria a cargo de Spicker, P. Álvarez y S. Gordon, D. Buenos Aires: CLACSO.

Cortina, A. Pereira, G. (Eds.) 2009. Pobreza y libertad. Erradicar la pobreza desde el enfoque de Amartya Sen. Madrid: Tecnos.

Escobar, A. 2007. La invención del tercer mundo. Construcción y deconstrucción del desarrollo. Caracas: Fundación Editorial El Perro y la Rana.

Freire, P. 2001. Pedagogía de la indignación. Madrid, Morata.

Jiménez, M. 2008. Aproximación teórica de la exclusión social: complejidad e imprecisión del término, consecuencias para el ámbito educativo. Estudios Pedagógicos 34(1): 173-186.

Juárez, M. Renes, A. et al. 1995. Población, estructura y desigualdad social. En $V$ Informe sociológico sobre la situación social en España. Madrid: Síntesis, Documentación social.

Kliksberg, B. 2011. Cómo enfrentar la pobreza y la desigualdad.
Suplemento Especial Página/12. 2 octubre 2011. Buenos Aires: Página/12.

Makowski, S. 2008. Juventud, espacio urbano y exclusión social. En Cordera R, Kuri R. Ziccardi A. (Coord.) Pobreza, desigualdad y exclusión social en la ciudad del siglo XXI. México. Siglo XXI.

Rahnema, M. 1991. Global poverty: a pauperizing myth. Interculture 24(2): 4-51.

Rubilar, G. 2013. Imágenes de alteridad. Reflexiones y aportes para el trabajo social en contextos de pobreza y exclusión. Santiago de Chile: Universidad Católica de Chile.

Saraví, G. 2009. Juventud y sentidos de pertenencia en América Latina: causas y riesgos de la fragmentación social. Revista Cepal (98): 47-65.

Sachs, W. 1990. The Archaeology of the Development Idea. Interculture 23(4): 1-37.

Sen, A. 1996. "Capacidad y bienestar". En Nussbaum, M. C. y Sen, A. (Comps.). La calidad de vida. México: Fondo de Cultura Económica. 54-83.

Sen, A. 2000. Desarrollo y libertad. Barcelona: Planeta.

Sen, A. 2004. "Los tontos racionales: una crítica de los fundamentos conductistas de la teoría económica". En Hahn F. y Hollis M. (Comps.). Filosofía y teoría económica. México: Fondo de Cultura Económica.

Vasilachis, I. 2003. Pobres, pobreza, identidad y representaciones sociales. Barcelona: Gedisa. 